\title{
Lessons Learned from the Teaching of IS Development
}

\author{
Filomena Lopes and Paula Morais \\ Universidade Portucalense, Porto, Portugal
}

\section{flopes@upt.pt pmorais@upt.pt}

\section{Executive Summary}

The importance of information systems as a strategic resource to organizations and the amazing rate of information system technology evolution are widely recognized. As a result, undergraduate courses in this field need frequent updating to remain effective. This article presents a model to restructure the teaching of information systems. This model has received inputs from students, teachers and ex-students of our Computation Department and also from the organizational staff that interacts with our students in their training posts. These inputs help us to identify the main gaps in our curriculum and the organizational necessities that concern information systems staff. The model identifies the main areas that are the basis of our curriculum proposal, as well as the main knowledge topics to be covered. We conclude that an information systems curriculum must have an organizational emphasis as big as, or greater than the technological one.

Keywords: information systems, information systems curriculum, teaching information systems, curriculum model, undergraduate courses

\section{Introduction}

This work describes our experiences over the years of teaching information systems (IS) and the lessons we have learned.

We teach a course entitled "Computation and Management". The first three years of the curriculum focus on core modules and the fourth offers a set of optional modules, which aim to present emergent paradigms and technologies. After completing all the modules, students must do a six-month training post. We present them with a set of projects for them to choose. In the last few years $49 \%$ of students have made their training posts in software houses and consulting firms, $13 \%$ in industrial organizations, $12 \%$ in research organizations, $9 \%$ in the health sector, and the others in different fields.

The difficulties felt by our students in their training posts help us to identify the organizational needs and the gaps in our curriculum. Organizations need IS people with technical and organizational skills to effectively conceptualize, develop and manage IS. Organizational survival is increasingly dependent on the ability to use information as a strategic and operational resource. A modern IS curriculum must reflect this need.

Material published as part of this journal, either on-line or in print, is copyrighted by the publisher of the Journal of Information Technology Education. Permission to make digital or paper copy of part or all of these works for personal or classroom use is granted without fee provided that the copies are not made or distributed for profit or commercial advantage AND that copies 1) bear this notice in full and 2) give the full citation on the first page. It is permissible to abstract these works so long as credit is given. To copy in all other cases or to republish or to post on a server or to redistribute to lists requires specific permission and payment of a fee. Contact Editor@JITE.org to request redistribution permission.
In this work we present a model to restructure the teaching of IS. The first section describes the background and main problems of our students in information systems development. The second section describes the necessary knowledge domains to support a curriculum model which can give IS undergraduate students the necessary skills for the effective management of the information resources of organizations. 


\section{Background}

We teach a course entitled "Computation and Management" in a private university in Portugal, The course aims to provide students with the skills necessary to conceptualize, develop, and manage information systems. We were the first Portuguese university to offer a "Computation and Management" course. The other universities focused more on computer science courses. We have been instructing specialists in information and management for almost twenty years. In that time we have felt the necessity for a course not limited to the technical side of information systems, but also considering organizational systems, behavior, management and strategy. Our curriculum has been guided by the different versions of the ACM Curriculum model, modified to suit Portuguese reality.

Every five years we restructure our curriculum and every year we adjust the programs and the optional modules. The choice of five years is due to the knowledge evolution in this dynamic field, and also to the governmental restrictions we have. Every time we restructure the curriculum, it must be submitted to the Education Ministry. Sometime it takes years to be approved.

In the past our emphasis was on operating systems and programming languages - the IT side. Over the last ten years, we have become aware of the difficulties our students faced when they went to the organizations hosting their training posts. One of the big problems they felt was the well-known gap between IT and business people (Alter, 2000). We then began to realize that our students have strong IT skills, but know little about organizations.

Our first approach to help them was to put a bigger emphasis on modules focusing on management and information systems development (ISD). We also decided to adopt the philosophy and phases of an ISD methodology, and we have selected SSADM (Eva, 1992). Our choice reflects the result of a survey carried out in 1990 of 196 organizations of the European Community (Lopes, 1990). In this survey, $62.5 \%$ of the organizations use ISD methods, most commonly SSADM. We then faced two problems: i) SSADM does not fit well with the majority of Portuguese projects, due to their dimension; ii) the students have difficulties in translating business language to SSADM language, and in most cases they were not able to relate the concepts of the SSADM models.

In an attempt to solve these problems, we developed an adaptation of SSADM to the Portuguese reality, using a road map of concepts to guide the work of students. That road map was also used to coordinate the programs of some disciplines more directly related to ISD.

Although the road map was a great help to students, it was not enough. Information systems are no longer seen as synonymous to computerized systems, but as work systems that often are supported by information technology (Alter, 1999b). They are not only tools to support operational activities, but they are key resources to achieve competitive advantage. Information systems people require both technical and organizational skills to conceptualize, develop and manage information systems (AITP(DPMA)/ACM/AIS, 1997).

The recognition of the evolution of IS, from work automation tool to strategic resource (Alter, 1999b; Galliers \& Baets, 1998; Hammer, 1990; Lucas, 1997; O'Brien, 2000), and the consequent organizational needs and demands led us to adapt our curriculum again, evolving to an organizational perspective, while obviously not ignoring the technological side.

That same orientation is now shared by other Portuguese universities, and was considered relevant by six of their main heads of IS/IT departments, in a debate around the future and status of IS teaching that took place in the first conference of the Portuguese Information Systems Association(2000) in October 2000 . 


\section{Teaching ISD - an Approach for the 21st Century}

The development of the new curricula received inputs from students, teachers and ex-students of the department, and also from organizations. We conducted several brainstorming meetings with our department staff, and also invited students to participate in the discussions of the requirements for the new curricula. Being involved in the process students are more motivated and react better to the changes.

The opinions of the people who supervise our students in the organizations during their training posts were also an important contribution to the process. They were able to point out the main difficulties felt by the students and their main knowledge gaps.

We also conducted a survey of former students to gather information about the skills they considered important as IS professionals, to learn which skills they thought were not present in their curricula, and to find out their main difficulties. The areas of programming languages, software development and mathematics presented no difficulties to them. The biggest difficulties were the areas of networking and telecommunications (mentioned by $16 \%$ of the former students) and organization theory (11\% of the former students).

During this process we also took into account the recommendations of well recognized associations such as the ACM and IRMA/DAMA (AITP (DPMA)/ACM/AIS, 1997; Cohen, 2000).

Our first aim was to define an integrated approach to activities starting from the organizational strategic definition to the implementation level of an information system in an organization. The starting point was a model developed by a teacher of the Department who has a long experience in IS consulting (Coelho, 2001). We then conducted several brainstorming meetings with the Department staff to discuss the model. The result of these meetings and a bibliographic review (Alter, 1999a; Alter, 2000;

Buckingham, 1987; Checkland, 1998; Galliers \& Baets, 1998; Hirschheim, 1996; Iivari, 1998; McLeod 1996) allowed us to achieve to the model in Figure 1.

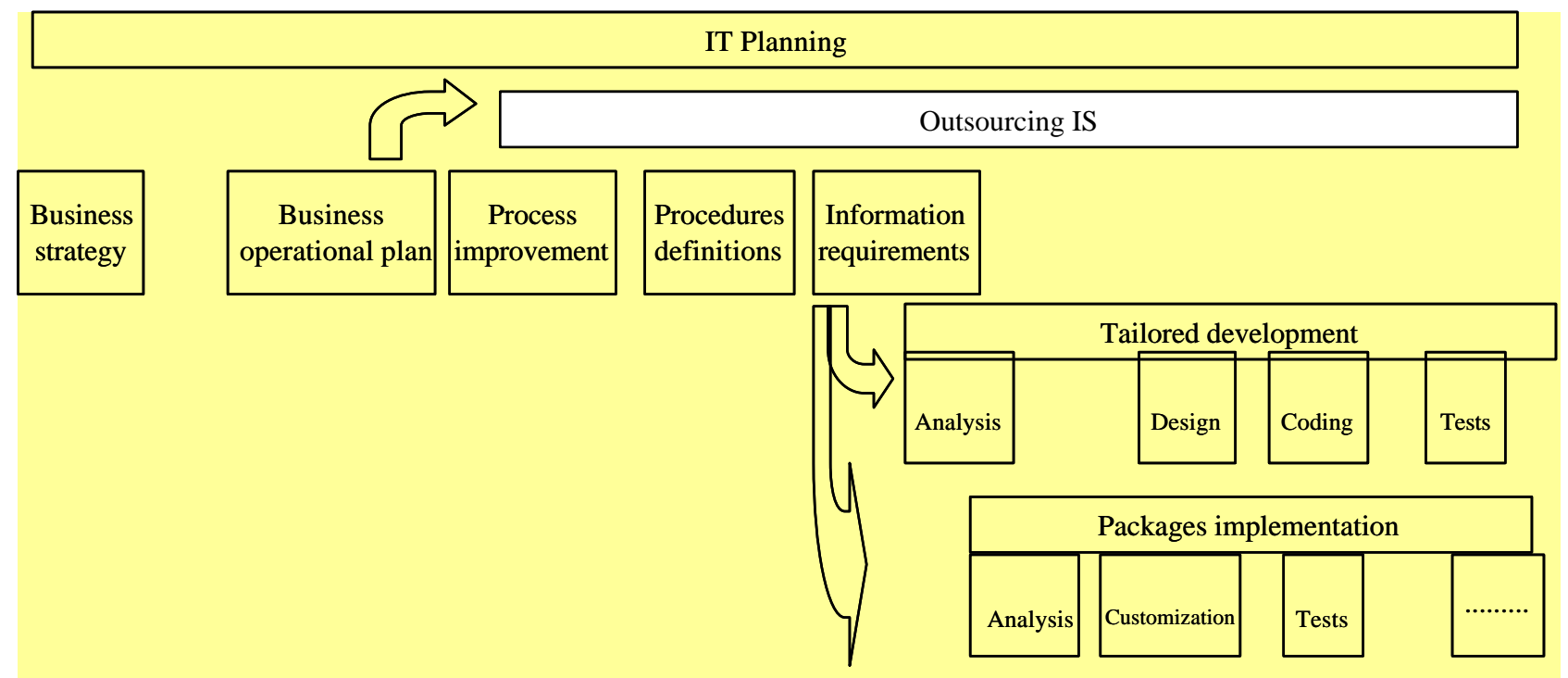

Figure 1: IS integrated approach

We have identified a set of the significant activities that must be carried out in any IS intervention so that a high level of quality is achieved. This set of activities is based on the assumption of a processoriented structure of organizations (Alter, 1999a; Davenport, 1993), and on an integrated view of management. The main activities identified relate the conception and development of an IS. With regard 
to development, two approaches can be followed, outsourcing or insourcing. Students must be able to manage an outsourcing project and also to develop an IS project. To accomplish this last kind of activity, two possible approaches are viable, tailored development and package implementation. Underlying all these activities are the planning and management of new, emergent and innovative information technology solutions.

The model in Figure 1 was a starting point to highlight the relevant knowledge areas that must be included in the curriculum in order to achieve the desired goals, that is teaching IS as a combination of management and technical perspectives, giving students a wider viewpoint of IS, allowing them to conduct continuous improvement of business processes. Another important point that drove us during this process was the idea that the new curriculum should be designed to support both traditional and emerging career opportunities.

Two main knowledge domains were automatically identified taking into account the requirements and skills needed by IS people: organization and technology.

The area named Organization focuses on the subjects of organizational theory, organizational mission, objectives and work and the application of information systems technology to achieve organizational strategy.

Technology involves the creative use of hardware and software platforms to support the information systems.

Those areas were further subdivided in significant sub-areas as presented in Table 1. Each sub-area was developed through consideration of the roles that IS professionals must play in organizations, for instance as CIO, systems analyst, IS project manager and IS consultant.

\begin{tabular}{|c|c|c|}
\hline Main & Sub-area & Main topics \\
\hline \multirow{19}{*}{ 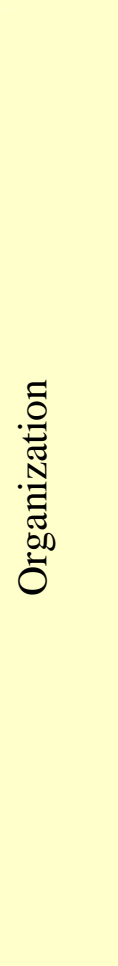 } & \multirow[t]{7}{*}{ Organizational theory } & Organizational models \\
\hline & & Organizational structure \\
\hline & & Organizational strategy \\
\hline & & Business processes \\
\hline & & Change management \\
\hline & & Knowledge management \\
\hline & & Decision making \\
\hline & \multirow[t]{2}{*}{ Systems theory } & Apply systems representations \\
\hline & & $\begin{array}{l}\text { Apply systems concepts to definition and } \\
\text { solution of problems }\end{array}$ \\
\hline & \multirow[t]{4}{*}{ IS intervention activities } & Continuous process improvement \\
\hline & & Business process reengineering \\
\hline & & Information systems planning \\
\hline & & Information systems development \\
\hline & \multirow[t]{4}{*}{ IS methodologies } & Systems development life cycles \\
\hline & & System planning methodologies \\
\hline & & System developing methodologies \\
\hline & & Outsourcing \\
\hline & \multirow[t]{2}{*}{ Project management } & Project planning \\
\hline & & Planning and resource management \\
\hline
\end{tabular}


Management of IS function Stages of growth

Aligning IT goals and strategy

Role of CIO

IS Security

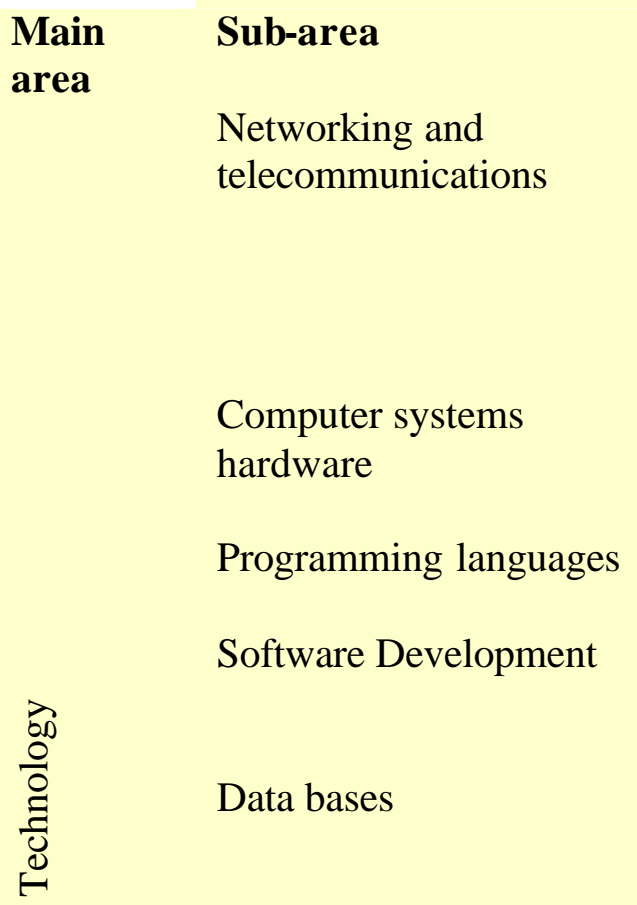

Operating systems

Software quality

Package implementation

IT and organizational

systems

\section{Main topics}

Networking concepts

Distributed systems

Internet, Intranets

Network management

Network security

Communication systems

Characteristics and capabilities of

computer systems

Systems architectures

Object and procedural programming

Fourth generation languages

Algorithms and data structures

Human computer interaction

Problem solving methods

Database design, implementation and

manage ment

Object, relational database systems

Data warehousing, data mining

Operating systems concepts

Network operating systems

Software metrics

Software tests

Packages selection

Integrated systems - ERPs

E-business

Supply-chain

Customer relationship management

Groupware

Integrating the enterprise

Table 1: Representative areas and knowledge expected for IS graduates

\section{Organizational theory}

The organizational theory sub-area intends to give students knowledge to explore the ways in which organizations are analysed as entities within an environment, as subjects of strategic action, as technologies, as social structures, as cultures, and as physical structures. It also covers important topics such as knowledge management, change management and decision-making.

\section{Systems theory}

Systems theory should provide the basic concepts of general system theory, together with some wellknown laws and principles, as well as other related topics such as viable systems and information theory. The application of systems theory to information systems is another important topic to consider. 


\section{IS intervention activities}

That sub-area intends to introduce the concepts and objectives concerning the activities that are carried out in organizations to change their information systems. They include continuous process improvement, business process reengineering (BPR), information systems planning (ISP) and information systems development (ISD).

\section{IS methodologies}

Students are presented with hard and soft, structured and object-oriented methodologies. The advantages of using different approaches are highlighted. Students should have the necessary knowledge so that they can choose and apply them in a specific situation. They must be also be knowledgeable about the outsourcing process, as frequently they will only need to know how to manage and purchase a service to a customer that will develop the required IS.

\section{Project management}

The project management sub-area is intended to give students the necessary knowledge to establish project goals, specify, gather, deploy and monitor resources and activities. Project costing, time, quality, documentation, leadership, motivation and team building are also skills students must learn.

\section{Management of IS function}

Students are expected to understand the internal management of information systems services from the point of view of the $\mathrm{CIO}$ and to examine alternative strategies and tactics available to management to achieve organizational goals. They should also have the necessary skills to coordinate the necessary activities to manage the operations of the IS function.

\section{Networking and telecommunications}

The networking and telecommunications sub-area should present the fundamental concepts, architectures, protocols, standards and security for the development and management of networks. Students are also expected to understand the technology of the Internet, intranets and extranets. Electronic commerce technology and distributed systems are also relevant topics to consider.

\section{Computer systems hardware}

The computer systems hardware sub-area provides the hardware background, describing the functions and components of computers and peripheral systems. The different types of architectures should be presented. Students should be able to install and configure computer systems for effective use in a business environment.

\section{Programming languages}

Students should gain in-depth knowledge of a number of object and procedural programming languages.

\section{Software development}

The software development sub-area provides the necessary skill to develop IS applications, including problem solving strategies, algorithm development, design and application of data structures and interface design.

\section{Data bases}

Students should gain the necessary knowledge to design, implement and manage database systems. This sub-area includes concepts such as data models, database administration, information retrieval, data warehouse and data mining. 


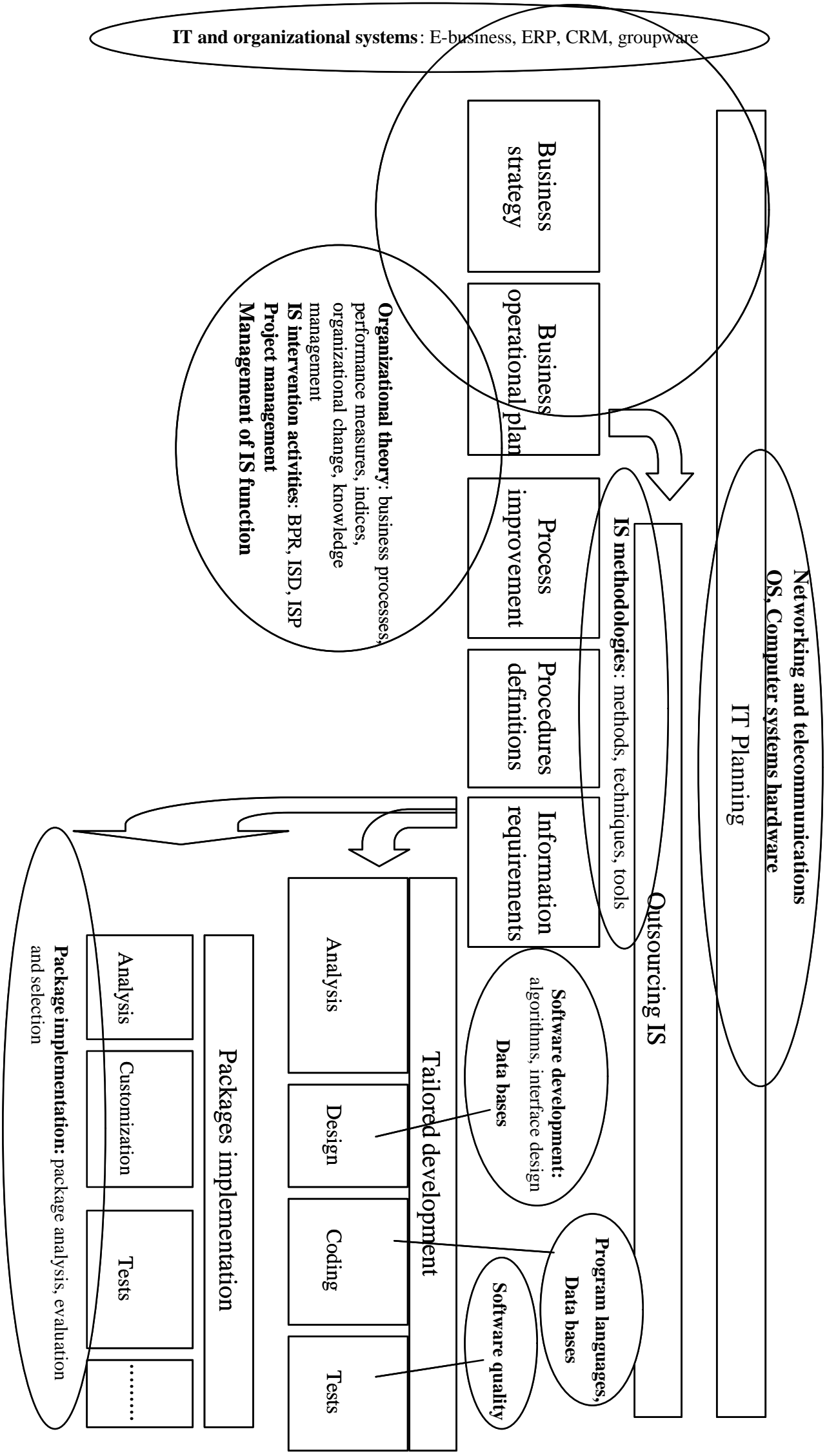

Figure 2: Curriculum sub-areas. 


\section{Operating systems}

The different types of operating systems (OS) will be studied and utilized. The main concepts relating the organization of OS are exposed as well as the interrelationship of OS and hardware and application systems.

\section{Software quality}

The verification and validation of programs is also an important topic. Principles to achieve high-level software quality are presented. Test planning and software metrics are relevant points to be covered.

\section{Package implementation}

Apart from knowing how to develop an IS, students should be able to purchase off the shelf applications. They should know how to select, analyse and evaluate packages.

\section{IT and organizational systems}

The IT and organizational systems sub-area provides an integrated view of the use of IT in an organization, with a specific interest on emergent technologies. Different kinds of systems should be analysed, such as enterprise resource planning, groupware, customer relationship management, supplychain and electronic commerce. Their role and impact in the organization should be studied.

Figure 2 presents the curriculum sub-areas related to the activities model, which was the basis of our curriculum proposal.

Although Table 1 only presents the main areas of organization and technology, the curricula also includes other complementary and interleaved topics and areas such as mathematics, economy, law, ethics, leadership and communication.

Modules are the building blocks of our curriculum. Each module may belong to one or more sub-areas. Each sub-area includes several modules. Figure 3 displays the weights of each area in our proposal according to the time allocated to the modules. The course is arranged in nine semesters with an average of twenty-four hours per week. The ninth semester is dedicated in full to a training post, developed in a Portuguese or foreign

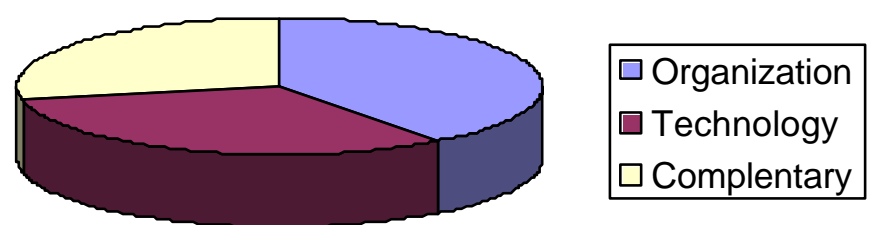

Figure 3: Curriculum main areas. organization.

One of our main goals is to give an integrated view of the IS knowledge domains. Students relate and exercise the concepts in the different sub-areas through integrated projects that should be developed in different modules. The training post gives them the most important holistic view of the knowledge acquired in the curriculum.

We have already used this curriculum model with a final training post, and once we have very good feedback from the students and the organizations, we intend to continue to use it.

\section{Conclusion}

Information systems are no longer seen as synonymous of computerized systems, but as work systems that often are supported by information technology. They are not only tools to support operational activities, but also key resources to achieve competitive advantage. Information systems curricula must 
reflect this reality and give students both technical and organizational skills to effectively conceptualise, develop and manage information systems.

Although it is our conviction that in an undergraduate curriculum we cannot teach every topic that will be needed by the students, we intend to give them the necessary background to support both traditional and emerging career opportunities and to promote continuous learning.

After identifying what we think are the necessary knowledge areas of any IS curricula that aims to satisfy organizational needs, we can still ask if the domains we have identified are the correct ones for the teaching of IS/IT in the 21st century.

We certainly have the idea that the new curricula must have an organizational emphasis as big as, or greater than the technological one.

\section{References}

AITP(DPMA)/ACM/AIS, (1997). IS'97 Model Curriculum.

Alter, S. (1999a). Information Systems (3rd ed.): Addison Wesley.

Alter, S. (1999b). A General, yet useful theory of Information Systems. Communications of the Association for Information Systems, 1, 69 .

Alter, S. (2000). Same Words, Different Meanings: are basic IS/IT Concepts our Self-Imposed Tower of Babel? Communications of the Association for Information Systems, 3.

Buckingham, R. A., Hirschheim, R. A., Land, F. F., \& Tully, C. J. (1987). Information Systems Curriculum: A basis for course design. Information Systems Education: Recommendations and Implementation, Cambridge University Press.

Checkland, P. and S. Holwell (1998). Information, systems and information systems: making sense of the field, John Wiley $\&$ Sons.

Coelho, J. (2001). A condução de projectos de sistemas de informação no âmbito de uma aproximação integrada de gestão o método LEARN. Paper presented at the QUATIC 2001, Lisboa, Portugal.

Cohen, E. (ed). Curriculum Model 2000 of the Information Resources Management Association and the Data Administration Managers Association, accessed (November 2000) from http://gise.org/IRMA-DAMA-2000.pdf.

Davenport, T. H. (1993). Process Innovation: Reengineering Work through Information Technology. Harvard Business School Press, Boston.

Eva, M. (1992). SSADM Version 4: a user's guide: McGraw-Hill.

Galliers, R., \& Baets, W. (1998). Information Technology and Organizational Transformation: Innovation for the 21st Century Organization: Wiley.

Hammer, M. (1990). Reengineering Work: Don't Automate, Obliterate. Harvard Business Review,4, 104-122.

Hirschheim, R., Klein, H., \& Lyytinen, K. (1996). Exploring the Intellectual Structures of Information Systems Development: a social Action Theoretic Analysis. Accounting, Management \& Information Technology, 6,1-64.

Iivari, J., R. Hirschheim, et al. (1998, June). A Paradigmatic Analysis Contrasting Information Systems Development Approaches and Methodologies. Information Systems Research. 9, 164-193.

Lopes, F. (1990). A Framework for the Selection of System Analysis \& Development Methods. M.Sc. Thesis, UMIST, Manchester.

Lucas, H. (1997). Information Technology for Management. (6th ed.): McGraw-Hill.

McLeod, R. Jr. (1996). Comparing Undergraduate Courses in Systems Analysis and Design. Communications of the ACM, $39,133-121$.

O'Brien, J. (2000). Introduction to Information Systems: Essentials for the Internetworked Enterprise. (9th ed.): McGraw-Hill

Portuguese Information Systems Association. (2000). conference 25-27 October. http://www.apsi.pt/1CAPSI/ 


\section{Biographies}

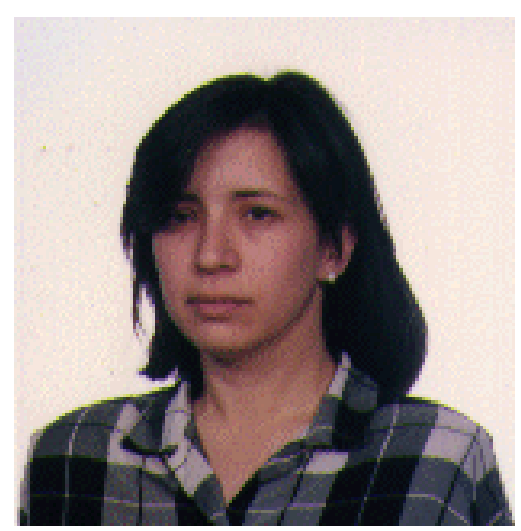

Filomena Lopes is a professor at the Computation Department of Universidade Portucalense, Porto, Portugal. She received her M.Sc. in Computation from UMIST, Manchester, and her Ph.D. in Information Systems and Technology from the Universidade do Minho, Portugal. Her research interests include information systems intervention activities, methods and models of IS and knowledge management. She has published several articles in proceedings of IS conferences. She is also engaged in several IS curriculum reformulations.

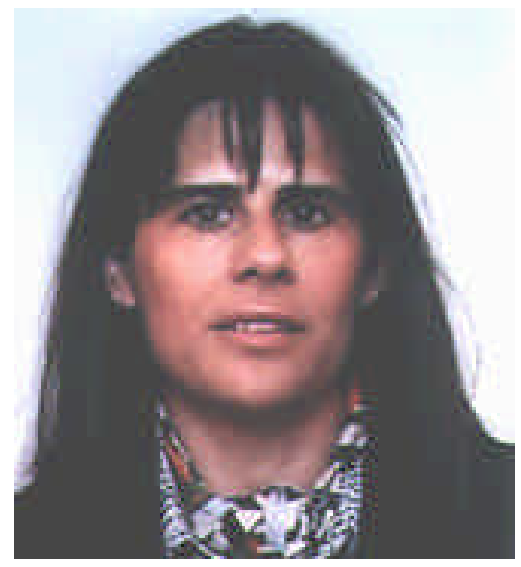

Paula Morais is a professor at the Computation Department of Universidade Portucalense, Porto, Portugal. She received her M.Sc. in Computation from UMIST, Manchester, and her Ph.D. in Information Systems and Technology from the Universidade do Minho, Portugal. Her research interests include information systems development, knowledge management and programming languages. She has published several articles in proceedings of IS conferences. She is also engaged in several IS curriculum reformulations. She is a member of AIS. 